\title{
SEVERAL INEQUALITIES FOR THE LARGEST SINGULAR VALUE AND THE SPECTRAL RADIUS OF MATRICES
}

\author{
SHU-QIAn SHEN AND TING-ZhU HUANG
}

Abstract. For nonnegative matrices $A=\left(a_{i j}\right) \in \mathbb{R}^{n \times m}, B=\left(b_{i j}\right) \in \mathbb{R}^{m \times n}$ and any $t \in[0,1]$, we present $\sigma\left(S_{t}(A, B)\right) \leqslant \sigma(A)^{t} \sigma(B)^{1-t}$, in which $S_{t}(A, B)=\left(a_{i j}^{t} b_{j i}^{1-t}\right)$ and $\sigma(\cdot)$ denotes the largest singular value. Using the result obtained, the inequality $\sigma(A \circ B) \leqslant \sqrt{\sigma(A \circ A) \sigma(B \circ B)}$ for matrices $A=\left(a_{i j}\right)$ and $B=\left(b_{i j}\right) \in \mathbb{C}^{n \times m}$ is established. Here, $A \circ B=\left(a_{i j} \bar{b}_{i j}\right)$, and $\bar{b}_{i j}$ denotes the complex conjugate of $b_{i j}$. Finally, some inequalities for the spectral radius are also studied.

Mathematics subject classification (2000): 15A18, 15A42, 15A57, 65F15, 65F99.

Key words and phrases: nonnegative matrix; largest singular value; spectral radius; inequality.

\section{REFERENCES}

[1] A. J. SCHWENK, Tight bounds on the spectral radius of asymmetric nonnegative matrices, Linear Algebra Appl., 75 (1986), 257-265

[2] R. S. VARGA, Matrix Iterative Analysis (Second Edition), Springer-Verlag, Berlin Herdelberg, 2000.

[3] L. YU. KolotiLINA, Lower bounds for the Perron root of a nonnegative matrix, Linear Algebra Appl., 180 (1993), 133-151.

[4] O. Rojo, R. Soto, H. Rojo, Bounds for the spectral radius and the largest singular value, Comput. Math. Appl., 36 (1998), 41-50.

[5] D. S. Mitrinovic, Analytic Inequalities, Springer-Verlag, New York, 1970.

[6] L. Elsner, D. HeRshKowitZ, A. PINKUS, Functional inequalities for spectral radii of nonnegative matrices, Linear Algebra Appl., 129 (1990), 103-130.

[7] S. KARLIN, F. OST, Some monotonicity properties of Schur powers of matrices and related inequalities, Linear Algebra Appl., 68 (1985) 47-65.

[8] R. A. Horn, C. A. Johnson, Matrix Analysis, Cambridge University Press, Cambridge, 1985.

[9] H. Minc, Nonnegative Matrices, Academic Press, New York, 1988.

[10] A. Berman, R. Plemmons, Nonnegative Matrices in the Mathematical Sciences, Academic Press, New York, San Francisco, London, 1979. 